\title{
Neuroprotection by Paeoniflorin against Nuclear Factor Kappa B-Induced Neuroinflammation on Spinal Cord Injury
}

\author{
Bin Wang, ${ }^{1,2}$ Wangying Dai, ${ }^{2}$ Lijun Shi, ${ }^{3}$ Honglin Teng, ${ }^{2}$ Xigong Li, \\ Jing Wang $\left({ }^{1},{ }^{2}\right.$ and Wujun Geng $\oplus^{5}$ \\ ${ }^{1}$ Department of Orthopedics, The Second Affiliated Hospital of Zhejiang Chinese Medical University, Hangzhou 310005, China \\ ${ }^{2}$ Department of Spine Surgery, The First Affiliated Hospital of Wenzhou Medical University, Wenzhou 325035, China \\ ${ }^{3}$ Department of Pharmacology, The First Affiliated Hospital of Wenzhou Medical University, Wenzhou 325035, China \\ ${ }^{4}$ Department of Orthopedic Surgery, The First Affiliated Hospital, School of Medicine, Zhejiang University, Hangzhou 310003, China \\ ${ }^{5}$ Department of Anesthesiology, The First Affiliated Hospital of Wenzhou Medical University, Wenzhou 325035, China
}

Correspondence should be addressed to Jing Wang; wjspine@163.com and Wujun Geng; gengwujun@126.com

Received 3 August 2018; Revised 23 October 2018; Accepted 25 October 2018; Published 2 December 2018

Academic Editor: Alfredo Conti

Copyright (C) 2018 Bin Wang et al. This is an open access article distributed under the Creative Commons Attribution License, which permits unrestricted use, distribution, and reproduction in any medium, provided the original work is properly cited.

\begin{abstract}
Background. Acute spinal cord injury (SCI) is one of the most common and devastating causes of sensory or motor dysfunction. Nuclear factor-kappa $\mathrm{B}(\mathrm{NF}-\kappa \mathrm{B})$-mediated neuroinflammatory responses, in addition to nitric oxide (NO), are key regulatory pathways in SCI. Paeoniflorin (PF), a major active component extracted from Paeonia roots, has been suggested to exert neuroprotective effects in the central nervous system. However, whether PF could improve the motor function after SCI in vivo is still unclear. Method. Immunohistochemical analysis, western blot, real-time quantitative PCR, immunofluorescence staining, and histopathological and behavioral evaluation were used to explore the effects of paeoniflorin after SCI for 14 days. Results. In this study, $\mathrm{PF}$ treatment significantly inhibited $\mathrm{NF}-\kappa \mathrm{B}$ activation and downregulated the expression of inducible nitric oxide synthase (iNOS), cyclooxygenase-2(COX-2), and Nogo-A. Comparing behavioral and histological changes in SCI and PF treatment groups, we found that PF treatment improved motor function recovery, attenuated the histopathological damage, and increased neuronal survival in the SCI model. PF treatment also reduced expression levels of Bax and c-caspase- 3 and increased the expression level of Bcl- 2 and cell viabilities. Upregulation of TNF- $\alpha$, IL-6, and IL- $1 \beta$ after injury was also prevented by PF. Conclusion. These results suggest that the neuroprotective effects of PF are related to the inhibition of the NF- $\kappa$ B signaling pathway. And PF may be a therapeutic strategy in spinal cord injury.
\end{abstract}

\section{Introduction}

Spinal cord injury (SCI) can produce a variety of sensory or motor dysfunction, resulting from several types of acute and chronic central nervous system trauma. SCI pathology is subcategorized into primary and secondary injury. Primary injury is irreversible physical injury to the spine, whereas secondary injury is a series of chemical, reversible secondary pathophysiological changes, including inflammatory reaction, ischemia, apoptosis, and cell and tissue oxidative stress. Neuroinflammatory response is thought to play a pivotal role in secondary injury after SCI $[1,2]$.

Nuclear factor-kappa B (NF- $\kappa \mathrm{B})$ is a key regulatory transcription factor in immunological inflammatory stress.
There are five proteins in the mammalian NF- $\kappa$ B family: p50, p52, RelA/p65, RelB, and c-Rel [3]. RelA, also known as NF- $\kappa \mathrm{B}$ p65, is a Rel-associated protein involved in NF$\kappa \mathrm{B}$ heterodimer formation and nuclear translocation and activation [3]. In most normal cells, NF- $\kappa \mathrm{B}$ is present as an inactive, I $\kappa \mathrm{B}$-compound conjugate in the cytoplasm [4]. Activation of NF- $\kappa \mathrm{B}$ occurs through the degradation of inhibitor kappa $B(\mathrm{I}-\kappa \mathrm{B})$ by various signaling mechanisms, causing it to enter the nucleus to combine with DNA and activate gene expression [4]. NF- $\kappa \mathrm{B}$ has been shown to transcribe the genes encoding proinflammatory cytokines (TNF- $\alpha$, IL-1 $\beta$, and IL-12), inducible nitric oxide synthase (iNOS), and cyclooxygenase-2 (COX-2) [5]. Previous studies have shown that NF- $\kappa B$ is activated following acute SCI [6] 
and knockdown of NF- $\kappa \mathrm{B}$ in the rat can improve motor function recovery after trauma [7]. Additionally, inhibition of NF- $\kappa \mathrm{B}$-mediated inflammatory responses in SCI rats may improve the hind limb function of rats [8].

After SCI, a series of molecular protein makes up a repulsive environment, which inhibits axons regeneration and nerve function recovery. NO synthase (NOS) is an iron-containing monooxygenase that exists in three isoforms, neuronal NOS (nNOS), endothelial NOS (eNOS), and inducible NOS (iNOS). NOS produces $\mathrm{NO}$ in vivo and catalyzes the generation of large number of neurotoxic NO molecules, resulting in neuronal cell hypoxia, edema, and apoptosis. The inflammatory stimuli (TNF- $\alpha$, IL-1 $\beta$, and NO derived from iNOS and COX-2) that promote the generation of prostaglandin E2 play a crucial role in the pathogenic processes involved with neurodegenerative diseases and posttraumatic inflammatory reactions after SCI $[9,10]$. Since iNOS is a downstream signaling molecule of the NF- $\kappa$ B pathway, iNOS expression may directly affect damage progress. Nogo-A is a well-known axons regeneration inhibitor [11]. The C-terminal of Nogo-A (Nogo-66) binds to Nogo-66 receptor (NgR) transducing the inhibitory signal, unfavorably affecting the cytoskeletal structure of axons and axon growth [12]. Inhibition of Nogo-A expression in rodent and primate model of SCI could promote regeneration of axons and improve functional recovery $[13,14]$.

Paeoniflorin (PF), a monoterpene glucoside, is the primary active chemical extracted from the roots of Paeonia plants. PF has been reported to have various bioactivities and function in immune regulation, such as the apoptosis induction [15], anti-inflammation [16, 17], immune regulation, pain-relief, and antioxidant activity [18]. Moreover, PF has been reported to have nerve protection effects. In the early 1990s, a Japanese scholar was the first to report that PF can improve learning and memory function decline in an animal model of dementia. Liu et al. found that PF protects microglia by inhibiting the NF- $\kappa$ B and VEGF/Flt-1 signaling pathways, suggesting a potential for use in treating Alzheimer disease (AD) [19]. Several studies have shown that PF has a central neuroprotective effect. However, most previous studies have concentrated on ischemic brain damage, Parkinson's disease, and used other in vitro experiments, including the use of PC12 cells [20], glial cells [21], and rat cerebral cortical neurons [22]. However, the effect of PF on motor function improvement after SCI and underlying molecular signaling proteins, in vivo, is yet to be reported. Therefore, the aim of this study was to elucidate the effect of PF on neuronal inflammation, oxidative stress, and repair of neurological function, via in vivo and in vitro studies of NF- $\kappa \mathrm{B}$ pathwaymediated inflammatory responses.

\section{Materials and Methods}

2.1. Animals. Young adult male and female healthy Sprague-Dawley (SD) rats, weighing 200 to 240 g, were obtained from the Animal Center of Chinese Academy of Sciences, Shanghai, China. At the beginning of the experiment, all animals were fed for 1 week in a standard temperature room $\left(23 \pm 0.5^{\circ} \mathrm{C}\right)$ and maintained on a 12-h light/dark cycle, with free access to an abundance of water and food. All animal care, breeding, and testing procedures accepted the supervision and inspection of Laboratory Animal Ethics Committee of Wenzhou Medical University and Laboratory Animal Centre of Wenzhou Medical University and fully complied with the Guide for the Care and Use of Laboratory Animals from the National Institutes of Health.

2.2. Spinal Cord Injury and PF Administration. Rats were randomly divided into one of the following three groups ( $n=30$ per group): (1) Sham, (2) SCI, and (3) SCI+PF. Rats were anaesthetized with an intraperitoneal injection of pentobarbital sodium $(40 \mathrm{mg} / \mathrm{kg})$. While fixed on an operating table, skin was prepared and sterilized with povidone iodine. The skin and muscle were incised along the spinous process, and a laminectomy was performed at T9 segmental level vertebrae to form a $2 \mathrm{~mm} \times 2 \mathrm{~mm}$ open area of the spinal cord. The exposed spinal cord received a crush injury using a vascular clip (15 g force; Oscar, China) for $1 \mathrm{~min}$. Sham rats were not injured and only laminectomy was performed. Hemostasis was used to close the wounds for all groups. Postoperatively, bladders were artificially emptied three times per day.

PF (purity $>98.0 \%$ ) was purchased from Solarbio (Solarbio Science \& Technology, Beijing, China) and dissolved in $0.9 \%$ saline solution. Beginning the day after surgery, Sham and SCI rats were intraperitoneally injected once per day with $0.9 \%$ saline, and PF rats were injected with $20 \mathrm{mg} / \mathrm{kg} /$ day paeoniflorin, until rats were sacrificed.

2.3. Motor Function Evaluation. Motor function was evaluated by two trained observers blinded to the experimental procedures, using the Basso-Beattie-Bresnahan (BBB) open field locomotor scale, inclined plane test, and footprint analysis at 1, 3, 7, and 14 days after injury. The range of $\mathrm{BBB}$ locomotor scale scores was from 0 (complete paralysis) to 21 (normal locomotion) [23]. The inclined plane test measures the maximum angle of the plane at which a rat could maintain itself for 5 s. Footprint analysis was performed by dipping the animal's hind paws in red dye and allowing it to walk on a walkway with a limited aisle $(100 \mathrm{~cm} \times 6.5 \mathrm{~cm})$. Footprints were recorded, and blotting paper was compared between three groups [24].

2.4. Tissue Preparation. At the designated time points (1, 3, 7 , and 14 days) after SCI, rats were deeply reanesthetized before being euthanized. Rats were transcardially perfused with physiological saline solution and $4 \%$ paraformaldehyde until the body became fixed. A $2.5-\mathrm{cm}$ section around the lesion epicenter of the spinal cord was removed and postfixed overnight by immersion in the same fixative. Next, the samples were embedded in paraffin and cut into $5-\mu \mathrm{m}$ thickness transverse and longitudinal sections. Paraffin sections were adhered to SuperFrost plus slides for immunohistochemistry, Hematoxylin-Eosin (HE) and Nissl staining.

2.5. Hematoxylin-Eosin (HE) and Nissl Staining. After deparaffinization, sections were hydrated in graded ethanol, followed by HE staining with hematoxylin and eosin at the 
lesion epicenter. In addition, sections were incubated with Nissl solution ( $0.1 \%$ Cresyl violet) for $20 \mathrm{~min}$ and visualized under a light microscope (BX53, Olympus, Japan) [25]. Neurons containing Nissl bodies were counted per section. Following HE staining, sections were given a pathological score ranging from $0-6$, based on the following: $0=$ no damage; $1=1-5$ eosinophilic neurons in gray matter; $2=$ 6-10 eosinophilic neurons in gray matter; $3=$ more than 10 eosinophilic neurons in gray matter; $4=$ less than $1 / 3$ infarction area of gray matter; $5=1 / 3-1 / 2$ infarction area of gray matter; $6=$ more than $1 / 2$ infarction area of gray matter.

2.6. Immunohistochemistry. Sections from samples obtained on days 1, 3, 7, and 14 after SCI were processed for IHC. Sections were blocked with 3\% hydrogen peroxide for $10 \mathrm{~min}$ and, after a 15-min rinse in fresh PBS, were boiled (at $98^{\circ} \mathrm{C}$ ) in $0.01 \mathrm{M}$ citrate buffer for $15 \mathrm{~min}$ for antigen retrieval, and then blocked with hydrogen peroxide for $60 \mathrm{~min}$. Subsequently, the sections were incubated with the following primary antibodies: iNOS (1:100, Abcam, USA) and COX-2 (1:100, Abcam, USA) overnight at $4^{\circ} \mathrm{C}$, followed by horseradish peroxidaseconjugated anti-rat secondary antibodies (1:200, Zhongshan Golden Bridge Biotechnology, Beijing, China). Finally, the immunoreactivity was observed with $0.05 \%$ diaminobenzidine (Zhongshan Golden Bridge Biotechnology, Beijing, China), and slides were then restained with hematoxylin, after being dehydrated and transparent, and mounted with 1 drop of neutral resin and cover slipped. Photographs of the ventral horn at a magnification of 400 were acquired using a biological imaging microscope (BX53, Olympus, Tokyo, Japan). Cells positive for iNOS and COX-2 were counted from five randomly selected images per section of the spinal anterior horn and analyzed with Image-Pro Plus. Primary antibodies were replaced by PBS for negative controls.

2.7. Western Blot Analysis. Total protein from cells and tissue was extracted by incubation in ice cold RIPA buffer containing $1 \mathrm{mM}$ PMSF and centrifuged at 12,000 rpm for $20 \mathrm{~min}$. Nuclear and cytosolic proteins were extracted using a Nuclear and Cytoplasmic Protein Extraction Kit (Beyotime), in accordance with the manufacturer's instruction. Proteins (30 $\mu$ g per sample) were separated by $10 \%$ sodium dodecyl sulfate (SDS)-polyacrylamide gel electrophoresis and electroblotted onto polyvinylidene difluoride (PVDF) membranes (Millipore, Billerica, MA, USA). Membranes were blocked with $5 \%$ fat-free dry milk for $2 \mathrm{~h}$ at room temperature and incubated overnight at $4^{\circ} \mathrm{C}$ with the following primary antibodies: NF- $\kappa \mathrm{B}$ p65 (1:1000, Abcam, USA), $\mathrm{I} \kappa \mathrm{B} \alpha$ (1:1000, Abcam, USA), iNOS (1:200, Abcam, USA), COX-2 (1:1000, Abcam, USA), Nogo-A (1:1000, Abcam, USA), Bcl-2 (1:1000, Abcam, USA), and Bax (1:800, Abcam, USA). Subsequently, membranes were incubated with the appropriate horseradish peroxidase-conjugated bovine antirat IgG secondary antibody (Beyotime). Protein bands were detected with enhanced chemiluminescent system ECL Plus (Thermo Scientific, USA). GAPDH or Histone 3 was used as a loading control. Band intensity was analyzed with Image J software (Media Cybernetics, Bethesda, MD, USA).
TABLE 1: Primer sequences for real-time PCR.

\begin{tabular}{lcc}
\hline Name & Primer & Sequence \\
\hline IL-1 $\beta$ & Forward & GACAAGAGCTTCAGGAAGGCAGTG \\
& Reverse & CACACTAGCAGGTCGTCATCATCC \\
TNF- $\alpha$ & Forward & TCCAGAACTCCAGGCGGTGTG \\
& Reverse & GTTCAGTAGACAGAAGAGCGTGGTG \\
IL-6 & Forward & AGCCACTGCCTTCCCTAC \\
& Reverse & TTGCCATTGCACAACTCTT \\
\hline
\end{tabular}

2.8. Cell Culture and Viability Assay. PC12 cells were obtained from the American Type Culture Collection (Rockville, MD, USA). Cells were seeded at a density of $2 \times 10^{5}$ cells $/ \mathrm{mL}$ in 6-well plates or $2 \times 10^{4}$ cells $/ \mathrm{mL}$ in 96 -well plates. To induce oxidative stress injury, $\mathrm{PC1} 2$ cells were incubated with different concentrations of $\mathrm{H}_{2} \mathrm{O}_{2}(0,50,100,200,400$ $\mu \mathrm{M})$ for $2 \mathrm{~h}$. For neuroprotective experiments, PC12 cells were pretreated with $\mathrm{PF}$ at various concentrations $(0,50$, 100,200 , and $400 \mu \mathrm{M}$ ) for $2 \mathrm{~h}$, followed by exposure to $\mathrm{H}_{2} \mathrm{O}_{2}(200 \mu \mathrm{M})$ stimulation. Cell viability was evaluated with a Cell Counting Kit-8 (CCK-8, Beyotime) following the manufacturer's instructions.

2.9. Real-Time Quantitative PCR. Total RNA was extracted from PC12 cells using TRIzol reagent (ThermoFisher Scientific, Waltham, MA, USA), according the manufacturer's instructions, and was verified by determining the absorbance at 260/280 $\mathrm{nm}$ using a spectrophotometer. Reverse transcription was performed using the Revert Aid First Strand cDNA Synthesis Kit (Thermo Scientific, Waltham, MA, USA). A sample of cDNA was used to quantify gene expression by qPCR using a SYBR Green (Bio-Rad, CA, USA) based PCR mixture on an CFX96TM Real-Time system. The amount of mRNA for each gene was normalized by $\beta$-Actin, and the relative expression levels were calculated using the $2-\Delta \Delta \mathrm{Ct}$ method. The sequences of all primers used for the real-time quantitative PCR experiments are presented in Table 1.

2.10. Immunofluorescence Staining. Immunofluorescence staining was conducted to analyze NF- $\kappa$ B protein expression inside and outside the nucleus. PC12 cells were fixed with $4 \%$ paraformaldehyde for 10 mins, washed 3 times in PBS, and permeabilized with $0.1 \%$ TritonX-100 for $10 \mathrm{~min}$. Subsequently, cells were incubated overnight at $4^{\circ} \mathrm{C}$, with the anti-NF- $\kappa \mathrm{B}$ antibody. After incubation with the secondary antibody (Zhongshan Golden Bridge Biotechnology, Beijing, China) for $1 \mathrm{~h}$ at room temperature, nuclei were counterstained with DAPI. Slides were imaged using a fluorescence microscope (DP70; Olympus, Tokyo, Japan).

2.11. Statistical Analysis. Unless indicated, the data are expressed as the mean \pm SEM. Statistical evaluation of the data was performed using Student's t test, or one-way analysis of variance (ANOVA) test followed by Dunnett's post hoc test. Statistical significance was accepted for $P$ values of $<0.05$. 


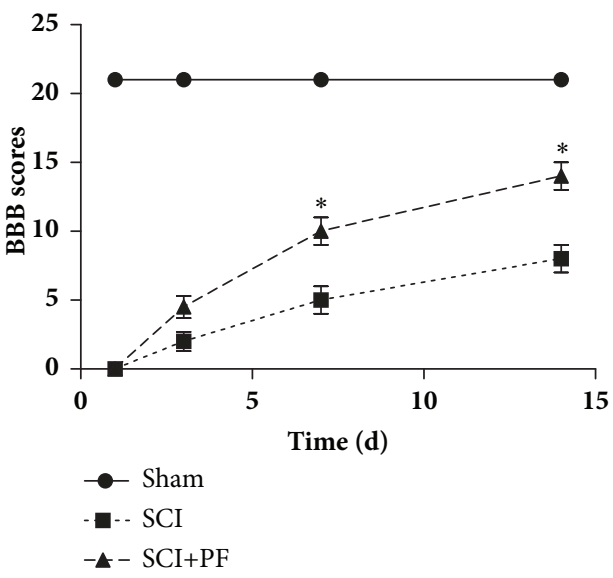

(a)

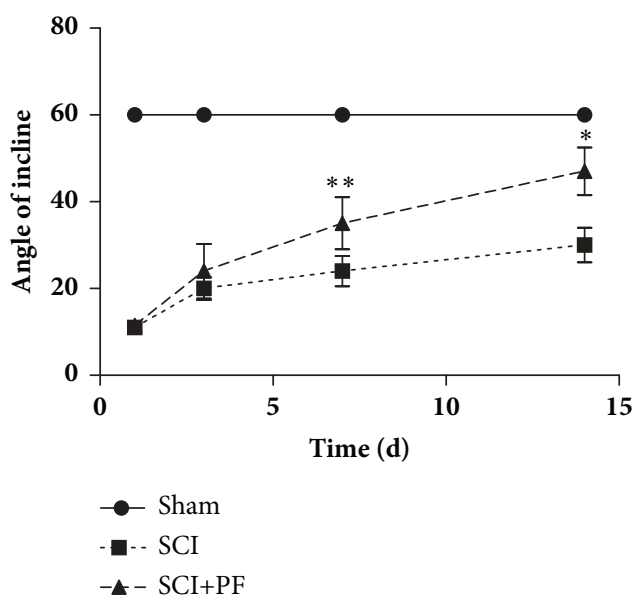

(b)

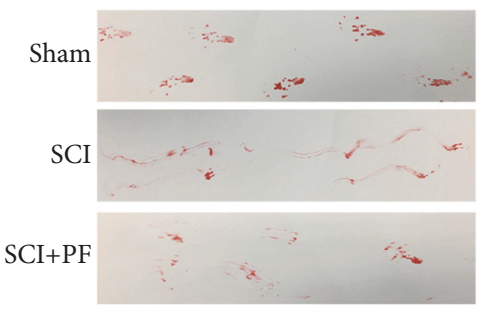

(c)

FIGURE 1: PF enhanced the functional recovery of hind paws on SCI rats. (a) Basso-Beattie-Bresnahan (BBB) open field locomotor scale and (b) inclined plane test. $* \mathrm{P}<0.01, * * \mathrm{P}<0.05$ compared with SCI group on the same day, $\mathrm{n}=10$. (c) Footprint text recorded the hind limbs footsteps of rats at 14 days after SCI.

\section{Results}

3.1. PF Enhanced Functional Recovery of Hind Limbs in SCI Rats. To determine if PF has a neuroprotective effect, we used the Basso-Beattie-Bresnahan (BBB) open field locomotor scale, inclined plane test, and footprint recordings to analyze the functional recovery of hind paws in SCI rats. SCI immediately induced hind limb paralysis and loss of bladder function, in all rats (SCI and PF groups). Forelimbs are not influenced. Two rats from the SCI group and one rat from the PF group did not survive the injury. Hence, we removed these three rats from all data analysis. As shown in Figures 1(a) and 1(b), hind limb function was significantly recovered in $\mathrm{PF}$ rats at 7 and 14 days $(\mathrm{P}<0.01)$, compared to SCI rats. No significant difference in BBB scores or angle of incline was observed between SCI and PF rats at 1 or 3 days $(\mathrm{P}>0.05)$. At the 14th day after injury, the PF rats were able to exercise joints and move with slight steps. As shown in the footprint recordings (Figure 1(c)), SCI rats had an irregular dragging gait, compared to that of the Sham group that had a normal conformity gait. To sum up, PF intervention enhanced walking function.

3.2. PF Reduced Neuronal Trauma and Histopathological Damage in Spinal Cord Tissue. To confirm the neuroprotective effect of PF, spinal cord tissue was HE and Nissl stained. As shown in Figure 2, in injured spinal cord, the center of the lesion was significant and lost its normal structure.
Denaturation, necrosis, and apoptosis were observed in gray and white matter, at transverse and longitudinal sections (Figure 2(a)). Specifically, in ventral neurons, we observed few or no Nissl bodies (Figure 2(b)). Compared to SCI rats, tissues obtained from $\mathrm{PF}$ rats had less morphological damage (Figure 2(c)), less areas of necrosis, infiltrated polymorphonuclear leukocytes and macrophages, and increased neuronal survival (Figure 2(d)). The results of HE and Nissl staining suggest that $\mathrm{PF}$ treatment reversed the destruction of spine cord.

3.3. PF Inhibited Nuclear Expression of NF- $\kappa B$ and Activation of $i N O S$ and COX2 in SCI Rats. We performed western blot analysis to examine expression levels of NF- $\kappa \mathrm{B}$ and associated proteins. Levels of NF- $\kappa \mathrm{B}$ and $\mathrm{I} \kappa \mathrm{B} \alpha$ were detected in the tissue homogenate obtained from rats in all groups. As shown in Figures 3(a) and 3(b), after SCI stress, we determined that nuclear NF- $\kappa \mathrm{B}$ was increased, and cytoplasmic NF- $\kappa \mathrm{B}$ and $\mathrm{I} \kappa \mathrm{B} \alpha$ (an inhibitory marker of NF- $\kappa \mathrm{B}$ ) was decreased significantly $(\mathrm{P}<0.01)$, compared to Sham rats in spine cord tissue. In contrast, levels of nuclear protein p65 were downregulated after $\mathrm{PF}$ treatment $(\mathrm{P}<0.01)$, whereas cytoplasmic protein $\mathrm{p} 65$ levels were upregulated $(\mathrm{P}<0.05)$.

Under normal conditions, without injury, iNOS and COX-2 expression was nearly undetectable. IHC staining indicated that levels of iNOS and COX-2 increased significantly after SCI (Figures 3(c) and 3(d); P<0.01). 


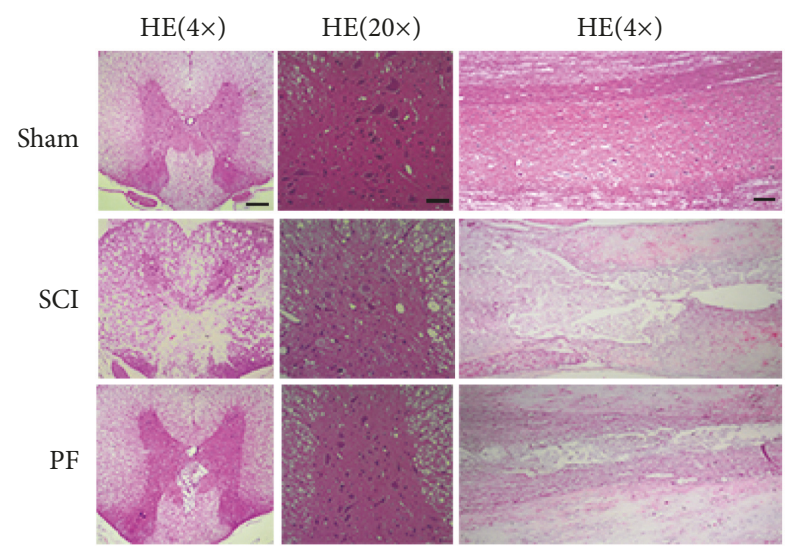

(a)

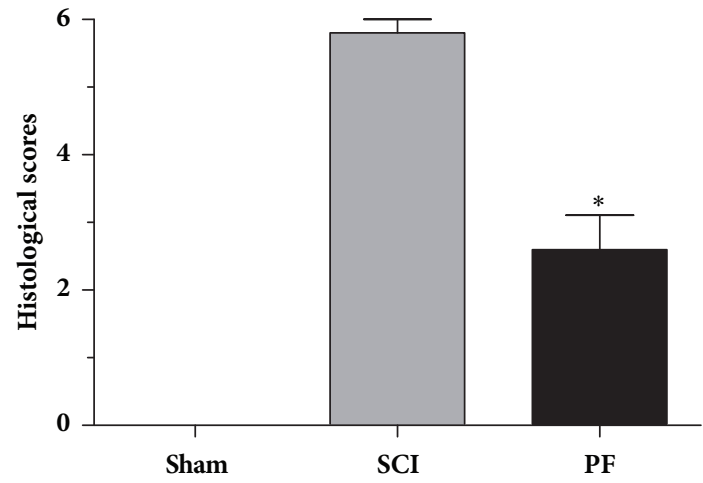

(c)

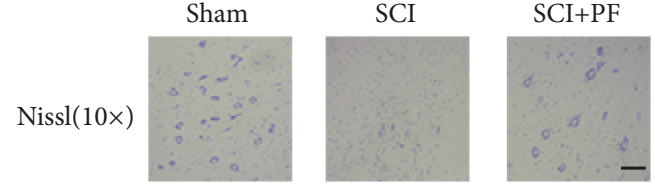

(b)

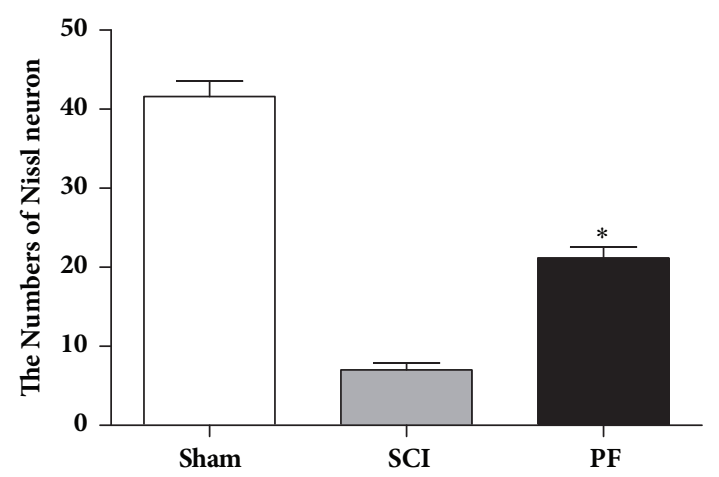

(d)

FIGURE 2: Hematoxylin-Eosin staining (HE) and Nissl staining. (a) Representative section for HE staining at 14 days after injury. Scale bar $200 \mu \mathrm{m}$ for Magnification $4 \times$, Scale bar $50 \mu \mathrm{m}$ for Magnification 20×. (b) Nissl staining to display the survival neurons. Scale bar $100 \mu \mathrm{m}$. (c) (d) Spine cord injury histological scores and statistics of the Nissl staining results. $* \mathrm{P}<0.01, * * \mathrm{P}<0.05$ compared with SCI group, $\mathrm{n}=5$.

These changes were significantly intervened by PF preconditioning. NF- $\kappa \mathrm{B}$-induced inflammation and oxidative stress proteins (iNOS and COX-2)-positive cells were gradually reduced by PF administration $7 \mathrm{~d}$ and $14 \mathrm{~d}$ after SCI $(\mathrm{P}<0.01)$. Additionally, the number of iNOS and COX-2positive cells in SCI rats was significantly increased with time following SCI $(\mathrm{P}<0.01$ or $\mathrm{P}<0.05)$. Next, to further analyze the relationship between the effects of PF and time following SCI, we compared positive cells of $14 \mathrm{~d}$ after PF administration to that of $7 \mathrm{~d}$ administration. No significant difference was found in iNOS and COX-2 expression after PF treatment at $7 \mathrm{~d}$ and $14 \mathrm{~d}(\mathrm{P}>0.05)$. Taken together, PF may alleviate the oxidative stress in the spinal cord.

3.4. PF Alleviated the Nogo-A Activation and Neuronal Apoptosis. The western blot assay results indicated that the expression of Nogo-A significant increased after SCI and reached the peak at 7 days (Figure 4(a), $\mathrm{P}<0.05$ ). Meanwhile, we found that $\mathrm{PF}$ treatment suppressed the expression of Nogo-A in spinal cord (Figure 4(a), $\mathrm{P}<0.01$ ). At first day after operation, there was no significant difference in activated Nogo-A expression among SCI, PF groups, and Sham group (Figure $4(a), P>0.05$ ). To further examine the neuronal apoptosis, we determined expression levels of Bax,
Bcl-2, and c-caspase-3, three proteins with a crucial role in apoptosis. We found that the proapoptotic protein Bax and c-caspase-3 significant increased, and antiapoptotic protein Bcl-2 decreased after SCI (Figures 4(b) and 4(c), $\mathrm{P}<0.01$ ). However, administration of PF upregulated the expression of $\mathrm{Bcl}-2(\mathrm{P}<0.01)$ and downregulated the expression of $\mathrm{Bax}$ $(\mathrm{P}<0.01)$ and cleaved-caspase $3(\mathrm{P}<0.05)$.

3.5. PF Protected PC12 Cells from $\mathrm{H}_{2} \mathrm{O}_{2}$-Induced Injury and Suppressed Inflammatory Responses. To further reinvestigate the relevance of in vitro findings and in vivo systems, we examined the effect of PF in oxidative-injured $\left(\mathrm{H}_{2} \mathrm{O}_{2}\right) \mathrm{PC1} 2$ cells. Results from green fluorescence protein orientation showed NF- $\kappa$ B aggregation in the cell nucleus after $\mathrm{H}_{2} \mathrm{O}_{2}$ stimulation, indicating the nuclear translocation process of NF- $\kappa$ B (Figure 5). Next, we have detected levels of inflammatory factors (TNF- $\alpha$, IL-6, and IL-1 $\beta$ ) with RT-qPCR. Compared to unstimulated cells, stressed PC12 cells had higher mRNA expression of proinflammatory cytokines including TNF- $\alpha$, IL-6, and IL- $1 \beta$ (Figure $6, \mathrm{P}<0.01$ ).

Upon pretreatment with PF, upregulation of TNF- $\alpha$, IL-6, and IL-1 $\beta$ at mRNA levels was prevented (Figure 6, $\mathrm{P}<0.01)$. These results show that $\mathrm{PF}$ may suppress neuroinflammatory responses via preventing nuclear translocation of 

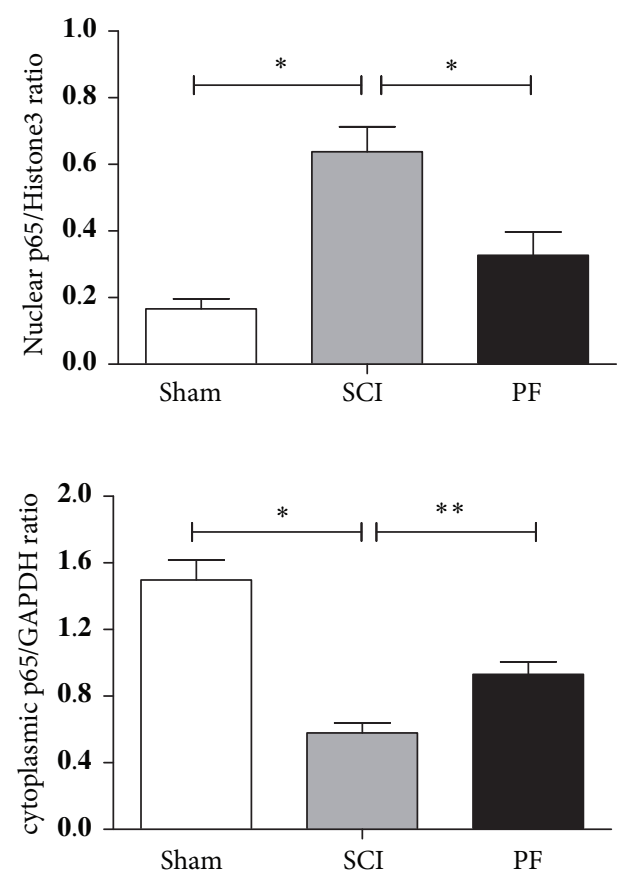

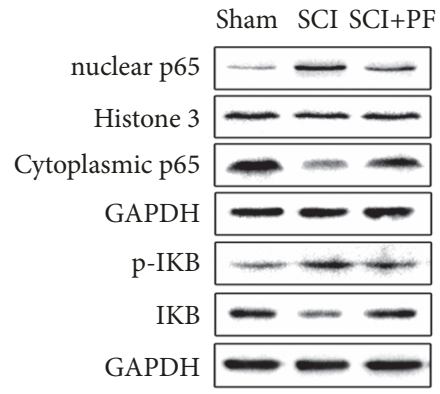

(a)

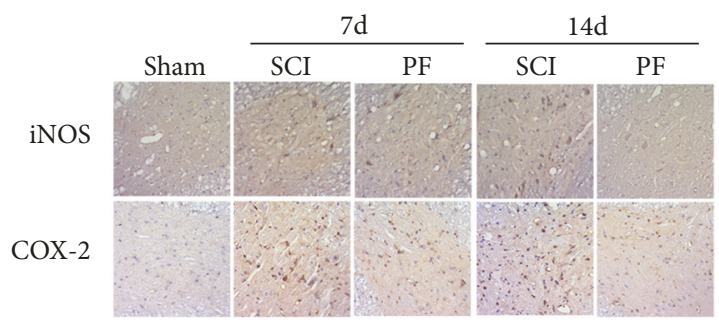

(c)

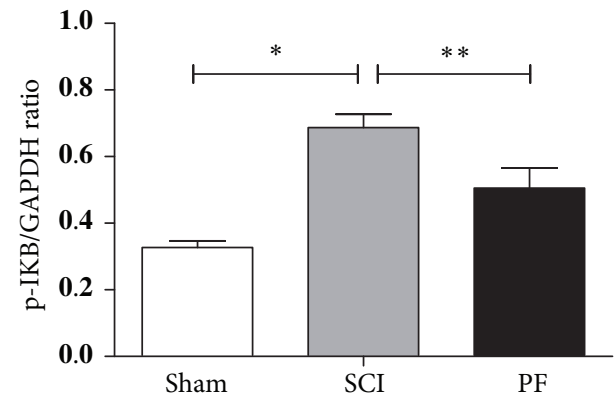

(b)

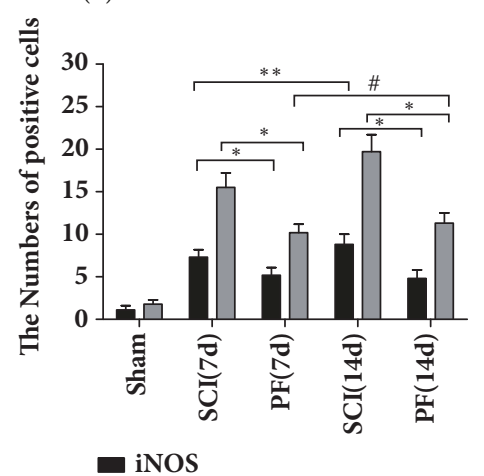

$\square$ COX-2

(d)

FIGURE 3: (a) Western blot analysis and quantification data of nuclear p65, cytoplasmic p65, phosphor-IKB, and IKB expression in each group of rats. (b) The optical density analysis of nuclear $\mathrm{p} 65$, cytoplasmic $\mathrm{p} 65$, phosphor-IKB, and IKB protein. $* \mathrm{P}<0.01$, $* * \mathrm{P}<0.05$ compared with SCI group, $n=5$. (c) Immunohistochemistry for iNOS and COX-2 in the Sham, $7 \mathrm{~d}$ and $14 \mathrm{~d}$ after spinal cord injury lesion and PF treatment $7 \mathrm{~d}$ and $14 \mathrm{~d}$ after injury groups. $* \mathrm{P}<0.01, * * \mathrm{P}<0.05, \# \mathrm{P}>0.05, \mathrm{n}=5$. (d) Analysis of the positive cells.

NF- $\kappa \mathrm{B}$ and reducing induction of proinflammatory cytokines.

3.6. PF Protected the PC12 Cells from $\mathrm{H}_{2} \mathrm{O}_{2}$-Induced Injury and Increased PC12 Cells Viability. In consistent with the result of western blot in vitro, $\mathrm{PF}$ preintervention significantly reduced $\mathrm{H}_{2} \mathrm{O}_{2}$-induced Bax levels and maintained Bcl-2 levels, which may be related to increased cell viability. Cell viability was determined using Cell Counting Kit-8. Predictably, PC12 cell viability decreased to different degrees after $\mathrm{H}_{2} \mathrm{O}_{2}$ stimulation 

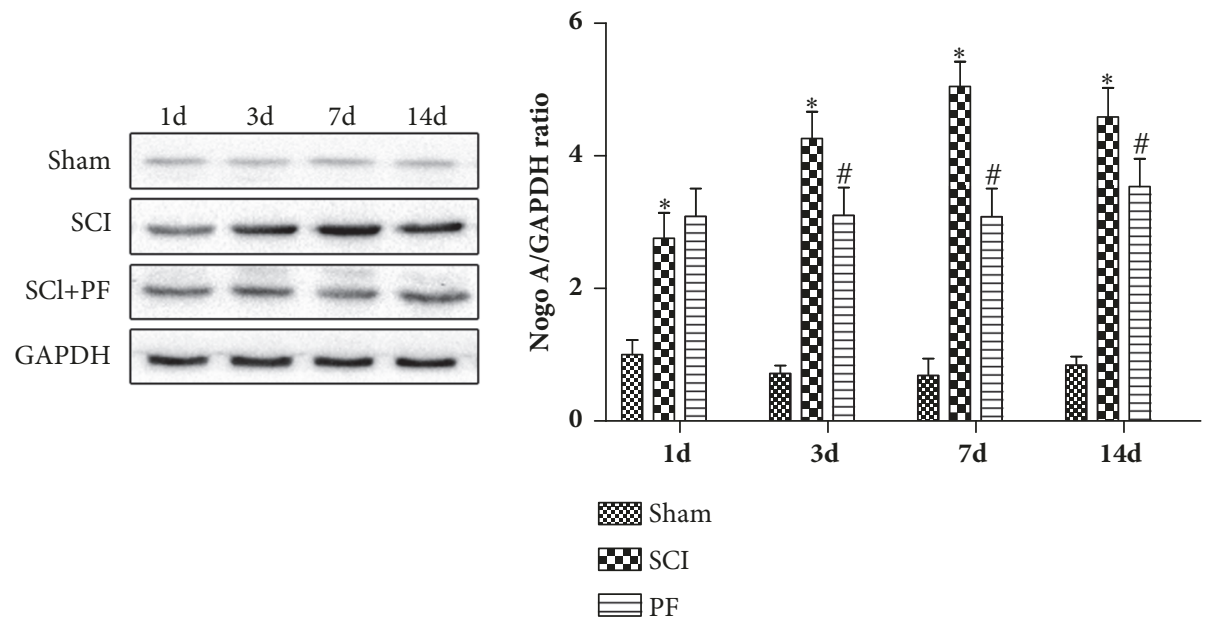

(a)

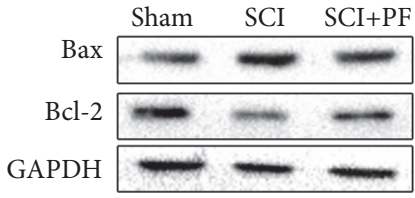

(b)

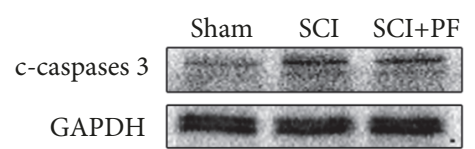

(c)

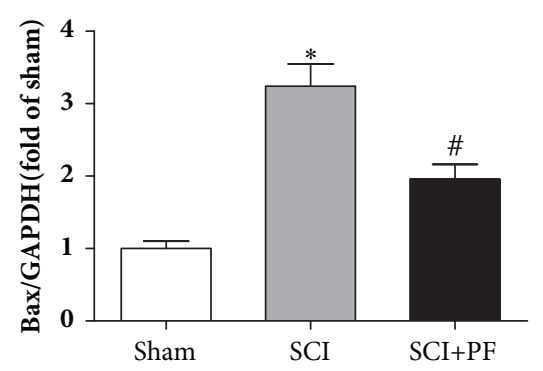

(d)

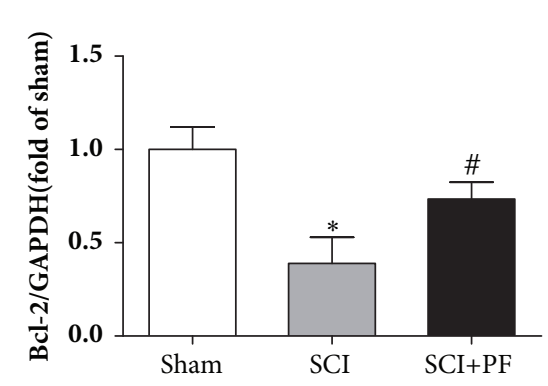

(e)

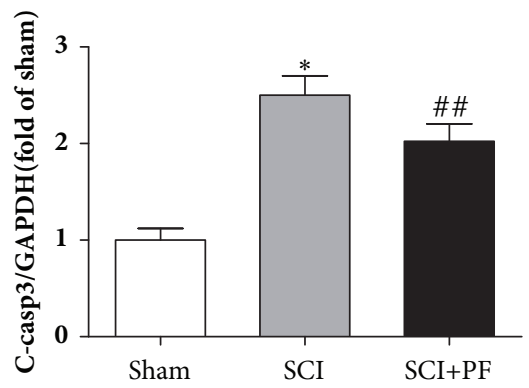

(f)

Figure 4: Western blot analysis and quantification data of Nogo-A, Bax, Bcl-2, and c-caspase-3 expression in each group of rats. $* \mathrm{P}<0.01$ versus the Sham group, $\# \mathrm{P}<0.01, \# \# \mathrm{P}<0.05$ versus the $\mathrm{SCI}$ group at the corresponding time points.

at concentrations of $0,50,100,200$, and $400 \mu \mathrm{M}$ for various intervals (Figure 7(e)). Next we examined the cytotoxicity of $\mathrm{PF}$ and found no significant difference in cell viability between controls and the single PF treatment group (400 $\mu \mathrm{M})(\mathrm{P}>0.05)$. To further confirm the neuroprotective effects of $\mathrm{PF}$ on oxidative stress, we pretreated PC12 cells with PF $(0,50,100$, and $200 \mu \mathrm{g} / \mathrm{ml}) 2 \mathrm{~h}$ before $\mathrm{H}_{2} \mathrm{O}_{2}$ stimulation $(200 \mu \mathrm{M})$ for $2 \mathrm{~h}$. We found that PF markedly inhibited $\mathrm{H}_{2} \mathrm{O}_{2}$-induced oxidative stress in a concentration-dependent manner (Figure 7(f)), suggesting that PF has a cytoprotective effect.

\section{Discussion}

Acute SCI is usually caused by injuries from traffic accidents and falling accidents and can result in permanent disability and serious injury. It is well known that motor function recovery following SCI is difficult. Operative treatment has been shown to be effective in relieving symptoms of nerve compression. However, there is still a dispute regarding effective methods to hinder secondary injury reactions and protect spinal neurons from trauma.

$\mathrm{PF}$ is the primary active chemical extracted from the roots of Paeonia plants and has been considered to exert protection effects on the central nervous system [21, 26]. Moreover, PF was reported to improve the behavioral performance and memory in the 1-methyl-4-phenyl-1, 2, 3, 6-tetrahydropyridine- (MPTP-) treatment mouse model of Parkinson's disease and alleviate cerebral ischemia injury [27].

PF has been shown to pass through the blood-brain barrier rapidly and protect the central nervous system by inhibiting NF- $\kappa \mathrm{B}$ in glial cells [28]. In this study, we used high purity (99\%) PF to ensure we observed its full effects and reduced errors. Our primary aim was to verify that PF treatment could reduce changes in inflammation-related proteins after SCI and, thus, protect the neuron from injury.

Inflammatory response and oxidative stress damage are important mechanisms of neuronal injury after SCI. Additionally, it is well known that NF- $\kappa \mathrm{B}$ (p65) and NO play 


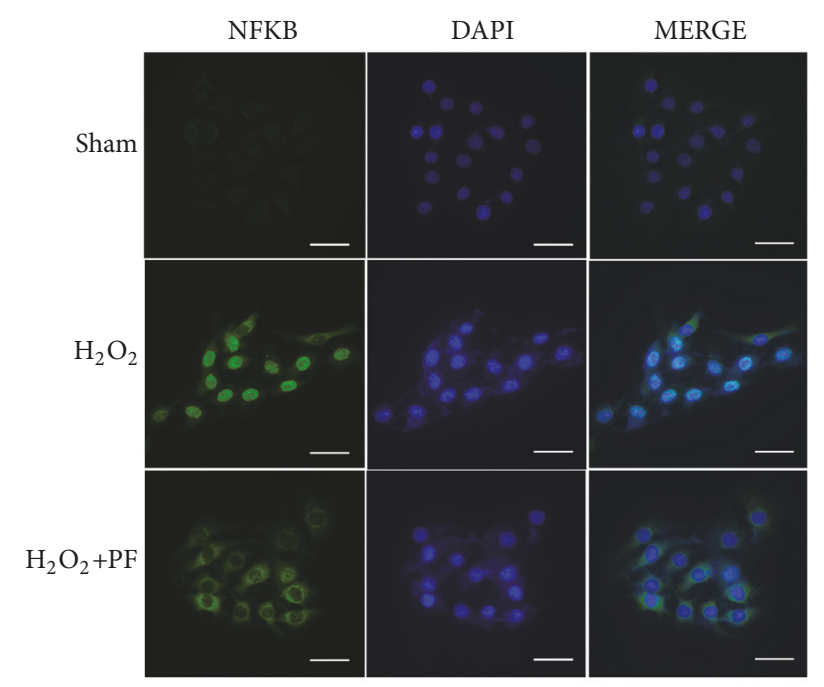

FIGURE 5: Immunofluorescence staining results of NF- $\kappa \mathrm{B}$ for PC12 cells. NF- $\kappa \mathrm{B}$ transcription is observed by (green) fluorescence localization; the nuclear is labeled by DAPI (blue). The bright blue nuclear in the right column is considered as positive staining NF- $\kappa \mathrm{B}$ which is activated; magnification was $\times 20$.

a pivotal role in secondary injury after SCI. Under normal conditions, NF- $\kappa \mathrm{B}$ is restricted in the cytoplasm by the inhibitory protein $\mathrm{I} \kappa \mathrm{B}$. A previous report indicated that ischemia induced overexpression of NF- $\kappa \mathrm{B}$ and degradation of its endogenous inhibitor $\mathrm{I} \kappa \mathrm{B} \alpha$ [29]. Ample evidence suggests that PF can suppress 6-hydroxydopamine- (OHDA) induced NF- $\kappa \mathrm{B}$ translocation and mitochondria-mediated apoptosis of PC12 cells [30]. Our results are consistent with those of previous studies. Specifically, after SCI, we observed overexpression of nuclear p65 (NF- $\kappa \mathrm{B})$ and decreased levels of cytoplasmic p65 and its endogenous inhibitor phosphorylated $\mathrm{I} \kappa \mathrm{B} \alpha$, and these changes were not observed in rats pretreated with $\mathrm{PF}$. We observed strong activation of NF$\kappa \mathrm{B}$ nuclear translocation following $\mathrm{H}_{2} \mathrm{O}_{2}$ stimulation, which was inhibited by PF treatment, suggesting that the NF- $\kappa \mathrm{B}$ signaling pathway plays an important role in PF-mediated neuroprotective effects.

COX-derived oxidative stress and NOS-derived nitrogen reactive species can be major factors in age-related inflammation [31]. Additionally, it has been hypothesized that an excess of NO, generated by iNOS, exposes gray matter neurons to highly toxic chemicals $[32,33]$. COX-2 is associated with proinflammatory stimuli, such as TNF- $\alpha$, IL- 6 , and IL- $1 \beta$ [34]. Additionally, NOS activity is modulated in early stages after NF- $\kappa$ B activation [35]. Furthermore, studies show that knockdown of iNOS in rat with SCI results in enhanced motor function compared to that in controls [32]. Our immunohistochemistry results demonstrate that PF treatment downregulated iNOS and COX-2 expression. However, the relationship of time of PF treatment is still unclear. In a previous study, we demonstrated that PF could modulate Th1/Th2 cell imbalances by regulating the expression of the transcription factors T-bet and Gata-3 in intervertebral disc degeneration rats. IFN- $\gamma$ and TNF- $\alpha$ of PF groups were

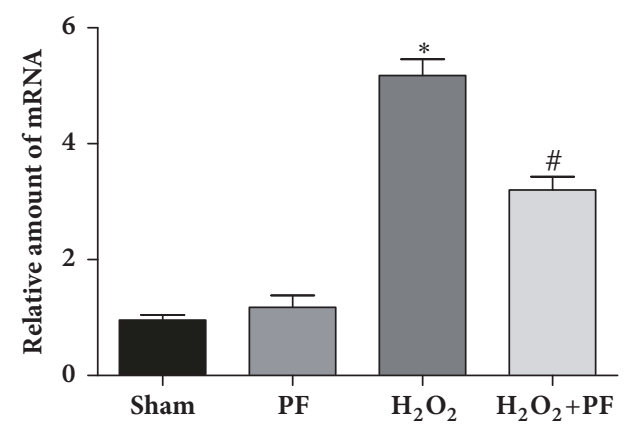

(a)

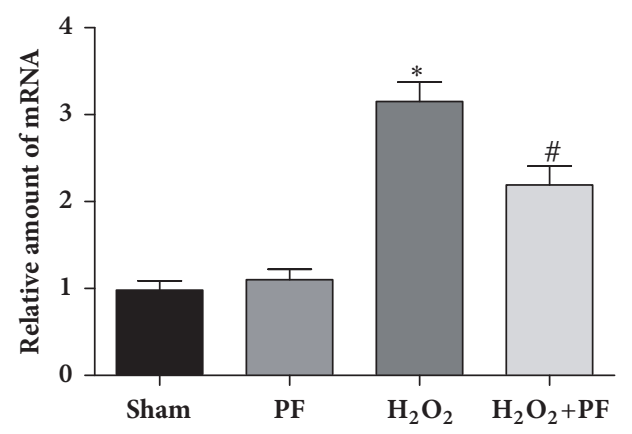

(b)

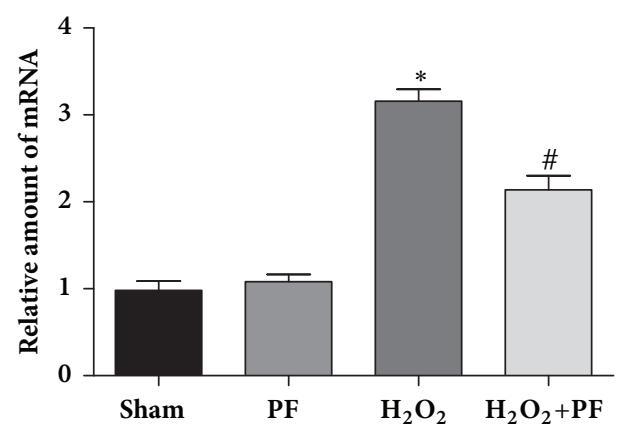

(c)

Figure 6: PF reduced $\mathrm{H}_{2} \mathrm{O}_{2}$-induced inflammatory factor in PC12 cells. PF prevented the increase of the mRNA expression of the inflammatory genes, such as IL- $1 \beta$, IL- 6 , and TNF- $\alpha$. PC12 were pretreated with $\mathrm{PF}(200 \mu \mathrm{M})$ for $2 \mathrm{~h}$ and then cultured with $200 \mu \mathrm{M}$ $\mathrm{H}_{2} \mathrm{O}_{2}$ for $2 \mathrm{~h}$. $* \mathrm{P}<0.01$ versus the Sham group, $\# \mathrm{P}<0.01$ versus the $\mathrm{H}_{2} \mathrm{O}_{2}$ group.

significantly decreased compared to those of the model group in a time-dependent manner over 3, 7, and 21 days. We previously found that PF could inhibit nucleus pulposus cell apoptosis and inhibit caspase- 3 and caspase- 9 activation by regulating Bcl-2 family protein [15]. To confirm this in vitro, $\mathrm{H}_{2} \mathrm{O}_{2}$ was used to simulate oxidative stress damage to activate $\mathrm{NF}-\kappa \mathrm{B}$ signaling pathways in PC12 cells. Additionally, in this study, we used RT-qPCR to further demonstrate the antiinflammatory effect of PF on PC12 cells and found that upregulation of TNF- $\alpha$, IL- 6 , and IL- $1 \beta$ was prevented at the mRNA level. In our in vitro experiment, PF treatment downregulated the expression of Bax and upregulated the expression of $\mathrm{Bcl}-2$. These results are all in agreement with those of $\mathrm{Wu}$ and Jin, who reported that PF treatment can 


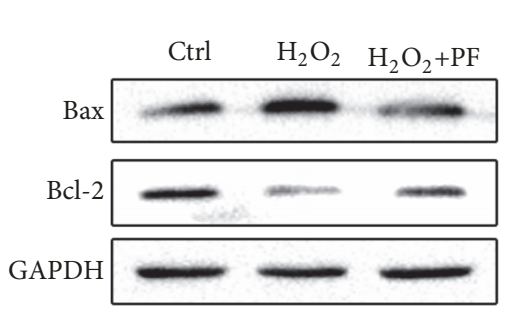

(a)

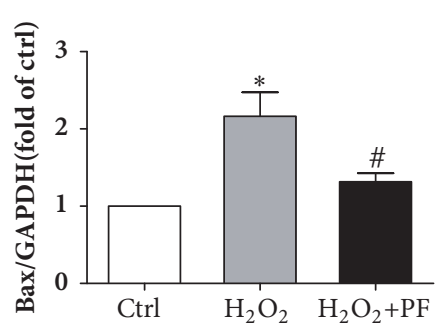

(b)

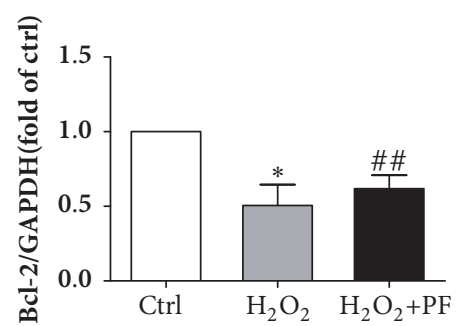

(c)

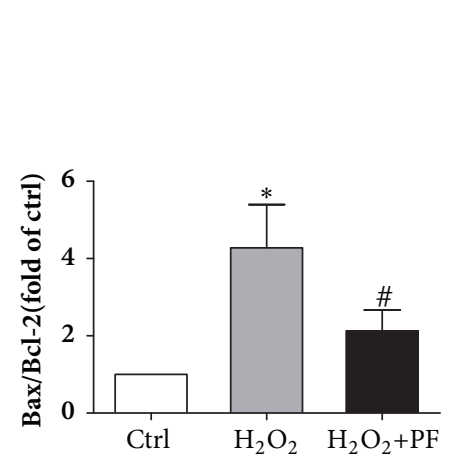

(d)

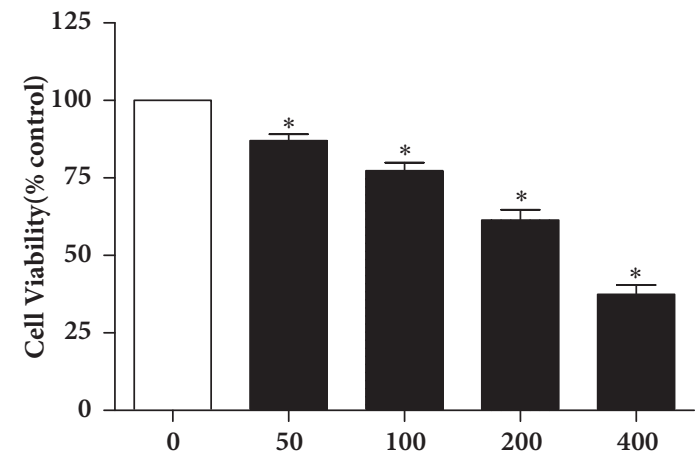

(e)

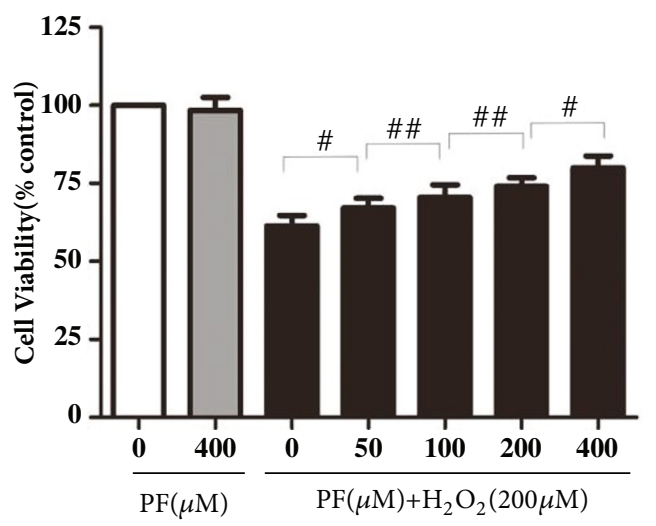

(f)

FIgURE 7: PF neuroprotection upon oxidative stress in PC12 cells. PC12 cells were either treated with $\mathrm{H}_{2} \mathrm{O}_{2}$ at indicated concentrations for 2 h. PC12 cells were treated with the indicated doses of paeoniflorin in the presence or absence of $200 \mu \mathrm{M} \mathrm{H}_{2} \mathrm{O}_{2}$. (a-d) Western blots to detect cell apoptotic. $* \mathrm{P}<0.01$ versus the control group, $\# \mathrm{P}<0.01$, \#\#P<0.05 versus the $\mathrm{H}_{2} \mathrm{O}_{2}$ group, $\mathrm{n}=5$. And (e, $\mathrm{f}$ ) Cell Counting Kit-8 analysis to detect cell viabilities. $* \mathrm{P}<0.01$ versus the control group, $\# \mathrm{P}<0.01, \# \# \mathrm{P}<0.05$ versus other treatment groups, $\mathrm{n}=5$.

inhibit apoptosis of NPC cells mediated by $\mathrm{H}_{2} \mathrm{O}_{2}$ [36]. The results of CCK-8 further confirmed that PF plays a cell protective effect in neuroinflammation damage.

When SCI happened, we observed that spinal structure was destroyed with great loss of nerve fibers. As one of the myelin related proteins in oligodendrocytes, Nogo-A is believed to be an inhibitor of nerve fiber impair when axon is injured [12]. It is generally accepted that C-terminal region (Nogo-66) of Nogo-A transduces the inhibitory signal into the cell interior of neurons by combining with Nogo-66 receptor $(\mathrm{NgR})$. The research reports that treatment with Nogo shRNAs, which can knockdown Nogo gene expression, improved function recovery of spinal cord injury rats [37]. In the present study, we found that PF treatment suppressed Nogo-A expression in the injured spinal cord. Meanwhile, we observed that tissues obtained from rats treated with PF had increased neuronal survival in the ventral horn of the spinal cord compared to SCI rats. This demonstrates a significant protective effect with less area of necrosis, consistent with the report showing that the neurological deficits and a robust loss caused by middle cerebral artery occlusion could also be inhibited by PF pretreatment [22]. After 1 week, treatment with $\mathrm{PF}$ progressively increased the locomotor function compared to SCI rats without PF treatment.

However, the present study still has some limitations. We focused on motor function recovery, which is dependent on motor neurons in the ventral horn. In paeoniflorin group, we found recovery of spontaneous voiding in some rats, but we did not evaluate the bladder function or calculate residual urine. We may add this research in future study. 
Other studies have described enhanced cell viability results after PF treatment compared to that observed in our study [30]. This may be due to the purity of PF, cell subculture, or the degree of $\mathrm{H}_{2} \mathrm{O}_{2}$ damage. Future research will be done on PF combined with nerve growth factor with epidural administration and synthesis biomaterials of sustainedrelease hydrogel. Additionally, we will attempt to determine the upstream and downstream sequence concrete mechanism of NF- $\kappa \mathrm{B}$ signaling pathway with PF intervention.

Although the neuroprotective effects of PF have been reported in animal models of neuropathology, no systematic investigation has reported that PF improves the motor function of SCI. We suggest that PF improves functional recovery of SCI rats for the first time. Currently, the major drug treatment for SCI is methylprednisolone (MP) aggressive therapy, which reduces inflammation response and neural edema of the spinal cord [38]. However, hormones cause many side effects, such as electrolyte disorder, aseptic bone necrosis, osteoporosis, and digestive tract symptoms [38]. We believe that PF has potential as a naturally derived treatment to reduce the progression of secondary injury and could be used as a therapeutic strategy in SCI in the future due to its dual effects of anti-inflammatory and neuroprotection.

\section{Conclusion}

Our study shows that treatment with PF reduced neuron axon trauma and histopathological damage of the spinal cord and increased the survival of neurons in the spinal cord lesions. Inhibition of NF- $\kappa \mathrm{B}$ signaling pathway may be involved in the neuroprotective effect of PF which enhanced the functional recovery of hind limbs of acute SCI model rats. PF treatment may be a therapeutic strategy in spinal cord injury. However, its detailed mechanism needs further study.

\section{Data Availability}

The data used to support the findings of this study are available from the corresponding author upon request.

\section{Conflicts of Interest}

The authors have no conflicts of interest to declare.

\section{Authors' Contributions}

Bin Wang and Wangying Dai have contributed equally to this work.

\section{Acknowledgments}

This work was supported by Medical and Health Technology Project of Zhejiang Province (2018KY124) and the National Natural Science Foundation of China (nos. 81200233 and 81774109).

\section{References}

[1] R. Hohlfeld, M. Kerschensteiner, and E. Meinl, "Dual role of inflammation in CNS disease," Neurology, vol. 68, no. 22, pp. S58-S63, 2007.
[2] A. Conti, S. Cardali, T. Genovese et al., "Role of inflammation in the secondary injury following experimental spinal cord trauma," Journal of Neurosurgical Sciences, vol. 47, no. 2, pp. 8994, 2003.

[3] Q. Li and I. M. Verma, "NF-kappaB regulation in the immune system," Nature Reviews. Immunology, vol. 2, no. 10, pp. 725734, 2002.

[4] N. D. Perkins, "Integrating cell-signalling pathways with NFkappa B and IKK function," Nature Reviews Molecular Cell Biology, vol. 8, no. 1, pp. 49-62, 2007.

[5] S. Liao, K. Zhou, D. Li, X. Xie, F. Jun, and J. Wang, "Schisantherin A suppresses interleukin- $1 \beta$-induced inflammation in human chondrocytes via inhibition of NF- $\kappa \mathrm{B}$ and MAPKs activation," European Journal of Pharmacology, vol. 780, pp. 6570, 2016.

[6] J. R. Bethea, M. Castro, R. W. Keane, T. T. Lee, W. D. Dietrich, and R. P. Yezierski, "Traumatic spinal cord injury induces nuclear factor- $\kappa \mathrm{B}$ activation," The Journal of Neuroscience, vol. 18, no. 9, pp. 3251-3260, 1998.

[7] D. S. Rafati, K. Geissler, K. Johnson et al., "Nuclear factor- $\kappa$ B decoy amelioration of spinal cord injury-induced inflammation and behavior outcomes," Journal of Neuroscience Research, vol. 86, no. 3, pp. 566-580, 2008.

[8] J. Hu, J. Huang, Z. Xiao, J. Li, X. Li, and H. Lu, "Tetramethylpyrazine accelerates the function recovery of traumatic spinal cord in rat model by attenuating inflammation," Journal of the Neurological Sciences, vol. 324, no. 1-2, pp. 94-99, 2013.

[9] G.-S. Jeong, D.-S. Lee, and Y.-C. Kim, "Cudratricusxanthone A from Cudrania tricuspidata suppresses pro-inflammatory mediators through expression of anti-inflammatory heme oxygenase-1 in RAW264.7 macrophages," International Immunopharmacology, vol. 9, no. 2, pp. 241-246, 2009.

[10] Y.-C. Chen, L.-L. Yang, and T. J.-F. Lee, "Oroxylin A inhibition of lipopolysaccharide-induced iNOS and COX-2 gene expression via suppression of nuclear factor- $\kappa \mathrm{B}$ activation," Biochemical Pharmacology, vol. 59, no. 11, pp. 1445-1457, 2000.

[11] M. E. Schwab, "Nogo and axon regeneration," Current Opinion in Neurobiology, vol. 14, no. 1, pp. 118-124, 2004.

[12] M. S. Chen, A. B. Huber, M. E. Van Der Haar et al., "Nogo-A is a myelin-associated neurite outgrowth inhibitor and an antigen for monoclonal antibody IN-1," Nature, vol. 403, no. 6768, pp. 434-439, 2000.

[13] T. Liebscher, D. Schnell, J. Scholl et al., "Nogo-A antibody improves regeneration and locomotion of spinal cord-injured rats," Annals of Neurology, vol. 58, no. 5, pp. 706-719, 2005.

[14] P. Freund, E. Schmidlin, T. Wannier et al., "Nogo-A-specific antibody treatment enhances sprouting and functional recovery after cervical lesion in adult primates," Nature Medicine, vol. 12, pp. 790-792, 2006.

[15] L. Shi, H. Teng, M. Zhu et al., "Paeoniflorin inhibits nucleus pulposus cell apoptosis by regulating the expression of Bcl-2 family proteins and caspase- 9 in a rabbit model of intervertebral disc degeneration," Experimental and Therapeutic Medicine, vol. 10, no. 1, pp. 257-262, 2015.

[16] W. Cao, W. Zhang, J. Liu et al., "Paeoniflorin improves survival in LPS-challenged mice through the suppression of TNF$\alpha$ and IL- $1 \beta$ release and augmentation of IL-10 production," International Immunopharmacology, vol. 11, no. 2, pp. 172-178, 2011.

[17] T. Chen, Z. Guo, X. Jiao et al., "Peoniflorin suppresses tumor necrosis factor- $\alpha$ induced chemokine production in human 
dermal microvascular endothelial cells by blocking nuclear factor- $\kappa \mathrm{B}$ and ERK pathway," Archives of Dermatological Research, vol. 303, no. 5, pp. 351-360, 2011.

[18] W.-L. Jiang, X.-G. Chen, H.-B. Zhu, Y.-B. Gao, J.-W. Tian, and F.-H. Fu, "Paeoniflorin inhibits systemic inflammation and improves survival in experimental sepsis," Basic \& Clinical Pharmacology \& Toxicology, vol. 105, no. 1, pp. 64-71, 2009.

[19] H. Liu, J. Wang, J. Wang, P. Wang, and Y. Xue, "Paeoniflorin attenuates Abetal-42-induced inflammation and chemotaxis of microglia in vitro and inhibits NF-kappaB and VEGF/Flt-1 signaling pathways," Brain Research, vol. 1618, pp. 149-158, 2015.

[20] M. Zheng, C. Liu, Y. Fan, D. Shi, and Y. Zhang, "Protective Effects of Paeoniflorin Against MPP+-induced Neurotoxicity in PC12 Cells," Neurochemical Research, vol. 41, no. 6, pp. 13231334, 2016.

[21] K. S. Huang, J. G. Lin, H. C. Lee, F. J. Tsai et al., "Paeoniae alba Radix Promotes Peripheral Nerve Regeneration," EvidenceBased Complementary and Alternative Medicine, Article ID 109809, p. 10, 2011.

[22] R.-B. Guo, G.-F. Wang, A.-P. Zhao, J. Gu, X.-L. Sun, and G. Hu, "Paeoniflorin protects against ischemia-induced brain damages in rats via inhibiting MAPKs/NF- $\kappa \mathrm{B}$-mediated inflammatory responses," PLoS ONE, vol. 7, no. 11, Article ID e49701, 2012.

[23] D. M. Basso, M. S. Beattie, J. C. Bresnahan et al., "MASCIS evaluation of open field locomotor scores: effects of experience and teamwork on reliability. Multicenter Animal Spinal Cord Injury Study," Journal of Neurotrauma, vol. 13, no. 7, pp. 343359, 1996.

[24] S.-P. Zhu, Z.-G. Wang, Y.-Z. Zhao et al., "Gelatin Nanostructured Lipid Carriers Incorporating Nerve Growth Factor Inhibit Endoplasmic Reticulum Stress-Induced Apoptosis and Improve Recovery in Spinal Cord Injury," Molecular Neurobiology, vol. 53, no. 7, pp. 4375-4386, 2016.

[25] H. Zhang, F. Wu, X. Kong et al., "Nerve growth factor improves functional recovery by inhibiting endoplasmic reticulum stressinduced neuronal apoptosis in rats with spinal cord injury," Journal of Translational Medicine, vol. 12, no. 1, article 130, 2014.

[26] Z.-Y. Hu, L. Xu, R. Yan et al., "Advance in studies on effect of paeoniflorin on nervous system," Zhongguo Zhongyao Zazhi, vol. 38, no. 3, pp. 297-301, 2013.

[27] M. Zheng, C. Liu, Y. Fan, P. Yan, D. Shi, and Y. Zhang, "Neuroprotection by Paeoniflorin in the MPTP mouse model of Parkinson/s disease," Neuropharmacology, vol. 116, pp. 412-420, 2017.

[28] J. Liu, D.-Z. Jin, L. Xiao, and X.-Z. Zhu, "Paeoniflorin attenuates chronic cerebral hypoperfusion-induced learning dysfunction and brain damage in rats," Brain Research, vol. 1089, no. 1, pp. 162-170, 2006.

[29] D. M. Chen, L. Xiao, X. Cai, R. Zeng, and X. Z. Zhu, "Involvement of multitargets in paeoniflorin-induced preconditioning," The Journal of Pharmacology and Experimental Therapeutics, vol. 319, no. 1, pp. 165-180, 2006.

[30] H. Dong, R. Li, C. Yu, T. Xu, X. Zhang, and M. Dong, "Paeoniflorin inhibition of 6-hydroxydopamine-induced apoptosis in PC12 cells via suppressing reactive oxygen species-mediated PKC delta/NF-kappa B pathway," Neuroscience, vol. 285, pp. 7080, 2015.

[31] H. Y. Chung, H. J. Kim, K. W. Kim, J. S. Choi, and B. P. Yu, "Molecular inflammation hypothesis of aging based on the antiaging mechanism of calorie restriction," Microscopy Research and Technique, vol. 59, no. 4, pp. 264-272, 2002.
[32] T. Suzuki, H. Tatsuoka, T. Chiba et al., "Beneficial effects of nitric oxide synthase inhibition on the recovery of neurological function after spinal cord injury in rats," Naunyn-Schmiedeberg/s Archives of Pharmacology, vol. 363, no. 1, pp. 94-100, 2001.

[33] M. Farooque, J. Isaksson, and Y. Olsson, "Improved recovery after spinal cord injury in neuronal nitric oxide synthasedeficient mice but not in TNF-alpha-deficient mice," Journal of Neurotrauma, vol. 18, no. 1, pp. 105-114, 2001.

[34] H. Sheng, J. Shao, E. B. Hooton, M. Tsujii, R. N. DuBois, and R. D. Beauchamp, "Cyclooxygenase-2 induction and transforming growth factor beta growth inhibition in rat intestinal epithelial cells," Cell Growth \& Differentiation, vol. 8, no. 4, pp. 463-470, 1997.

[35] J. Isaksson, M. Farooque, and Y. Olsson, "Improved functional outcome after spinal cord injury in iNOS-deficient mice," Spinal Cord, vol. 43, no. 3, pp. 167-170, 2005.

[36] Y.-M. Wu, R. Jin, L. Yang et al., "Phosphatidylinositol 3 kinase/protein kinase $\mathrm{B}$ is responsible for the protection of paeoniflorin upon $\mathrm{H} 2 \mathrm{O} 2$-induced neural progenitor cell injury," Neuroscience, vol. 240, pp. 54-62, 2013.

[37] G.-M. Liu, Y.-G. Luo, J. Li, and K. Xu, "Knockdown of Nogo gene by short hairpin RNA interference promotes functional recovery of spinal cord injury in a rat model," Molecular Medicine Reports, vol. 13, no. 5, pp. 4431-4436, 2016.

[38] T.-L. Wang, B. Gu, H.-N. Li, G.-F. Zhang, and S. Zhang, "Inflammatory response and anti-inflammatory therapy after acute spinal cord injury," Chinese Pharmacological Bulletin, vol. 31, no. 4, pp. 452-457, 2015. 


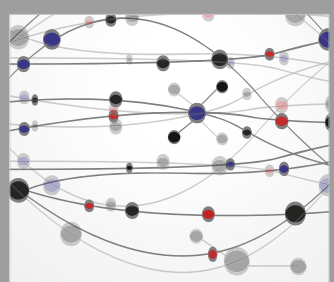

The Scientific World Journal
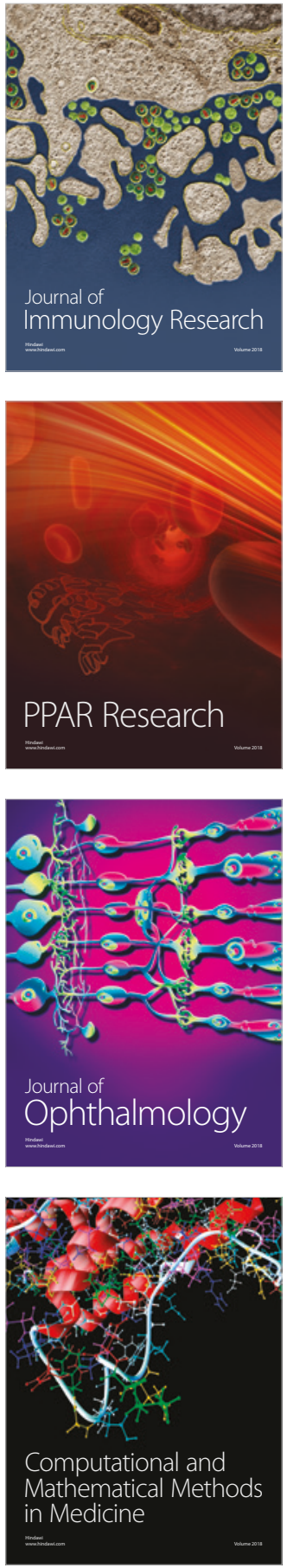

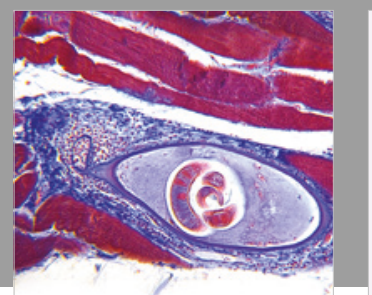

Gastroenterology Research and Practice

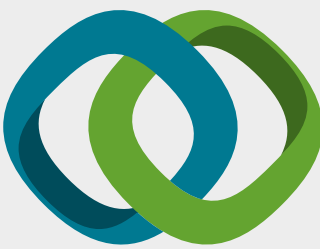

\section{Hindawi}

Submit your manuscripts at

www.hindawi.com
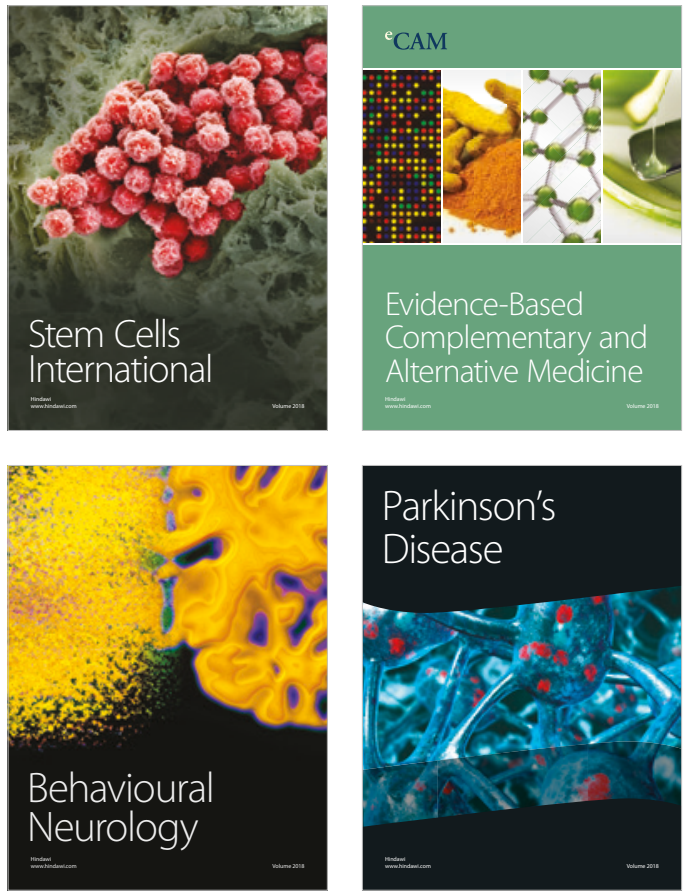

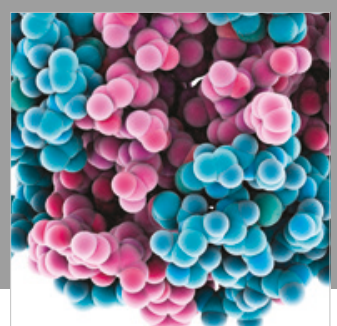

ournal of

Diabetes Research

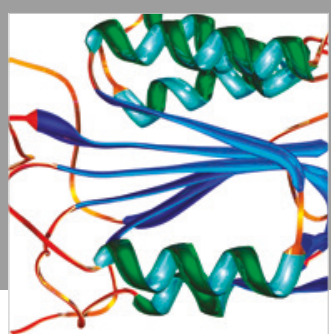

Disease Markers
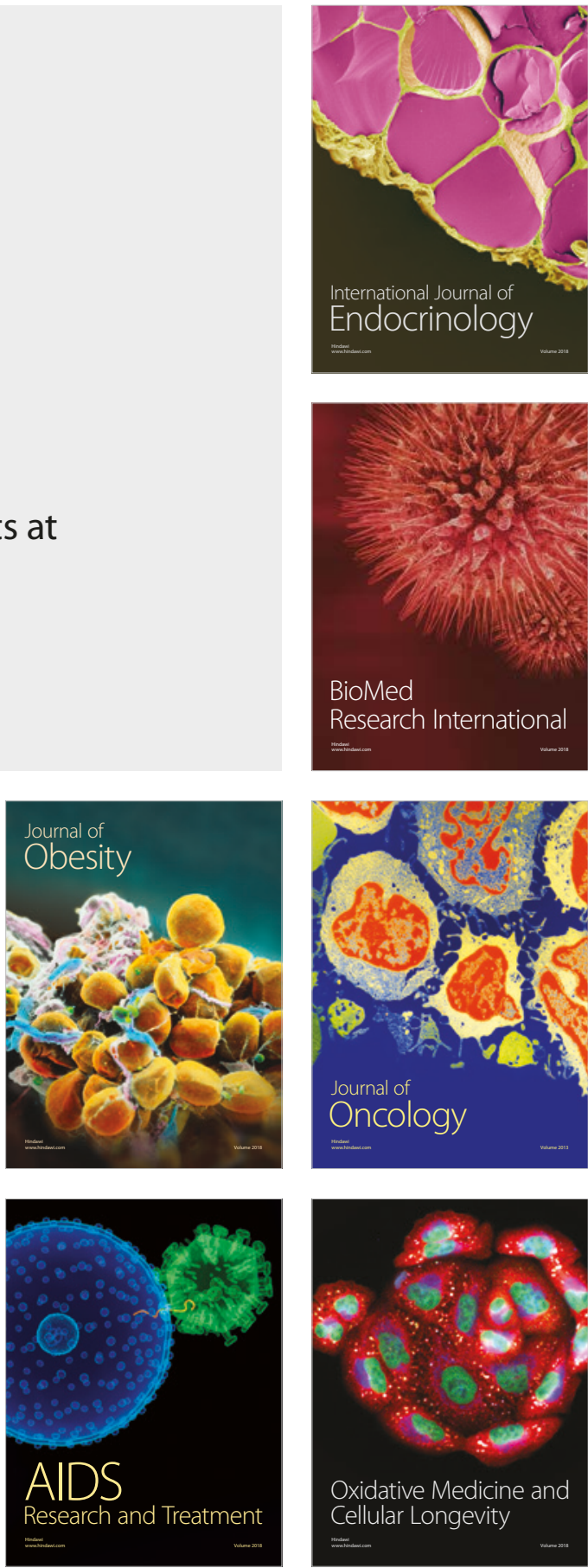